Bangladesh J. Bot. 48(1): 33-42, 2019 (March)

\title{
QUANTIFICATION OF G × E INTERACTION FOR FEED BARLEY GENOTYPES BY PARAMETRIC AND NON-PARAMETRIC MEASURES
}

\author{
Ajay Verma*, V Kumar, AS Kharab and GP Singh \\ Statistics and Computer Center, ICAR-Indian Institute of Wheat \\ and Barley Research, Karnal 132001, Haryana, India
}

Keywords: Parametric, Non-parametric measures, Rank correlation, Biplot analysis, Hierarchical clustering

\begin{abstract}
Genotype $\times$ environment $(\mathrm{G} \times \mathrm{E})$ interaction of 28 feed barley genotypes in 12 environments was quantified by the parametric and non-parametric measures. Significant differences among $G \times E$, environments and genotypes were observed as $42.3 \%$ of the total variance accounted for interaction effect. Interaction Principal Component Axes (IPCA1, IPCA2, IPCA3 and IPCA4) contributed 32.2, 20.3, 15.6 and $10.5 \%$ of the interaction sum of squares. Crossover interaction among genotypes and environments was confirmed by positive and negative values IPCAs. RD2786 followed by RD2876 had large negative IPCA1 score along with positive IPCA3 and IPCA4 values. Desirable genotypes were arranged in ascending order by D values as G23 (1.32) < G2 (1.42) < G20 (1.47) < G21 (1.63). The least AMMI Stability Value (ASV) score was observed for KB1367 followed by JB290 for yield performance. Smallest Pi was satisfied by BH 946, HUB 113 and RD2552. Environmental variance and CV identified non-stable performance of RD2874 and NDB1578 along with RD2876. Wricke's ecovalence showed UPB1040 and UPB1042 as promising genotypes. Nonparametric measures $\left(\mathrm{S}_{\mathrm{i}}{ }^{1}, \mathrm{~S}_{\mathrm{i}}{ }^{2}, \mathrm{~S}_{\mathrm{i}}{ }^{3}, \mathrm{~S}_{\mathrm{i}}{ }^{4}\right)$ pointed towards UPB1040 and PL881 for stable and unstable genotypes, however, $\mathrm{S}_{\mathrm{i}}{ }^{5}, \mathrm{~S}_{\mathrm{i}}{ }^{6}$ selected UPB1040 and UPB1042 as of stable yield. More or less similar results were observed by parametric as well as non-parametric measures.
\end{abstract}

\section{Introduction}

Barley (Hordeum vulgare L. ssp. vulgare) has been cultivated as the world's fourth important cereal crop owing to broader environmental adaptation as compared to other cereals. Multifarious uses of barley as a feed, food and malt for brewing industries have been well known in world wide. Barley is popularly grown as feed in many parts of the world including Indian subcontinent. Feed barley genotypes are evaluated in multi-environment trials (MET) to select the promising genotypes for specific environments. $\mathrm{G} \times \mathrm{E}$ interaction in MET helps to evaluate stable performance of genotypes (Sisay and Sharma 2016). Large numbers of stability measures were been observed (Mohammadi et al. 2016). Crop improvement programs incorporate both parametric and non-parametric approaches (Mohammadi and Ahmed 2008). Several parametric methods including univariate and multivariate are the environmental variance $\left(\mathrm{S}_{\mathrm{yi}}^{2}\right)$ (Lin et al. 1986), Wricke's ecovalence $\left(\mathrm{W}_{\mathrm{i}}{ }^{2}\right)$ (Wricke 1962) and the coefficient of variability $\left(\mathrm{CV}_{\mathrm{i}}\right)$ (Francis and Kanenberg 1978), AMMI stability value (ASV) (Purchase et al. (2000). Ranks of genotypes as per their yield performance across environments used to calculate non-parametric measures as suggested by Huehn (1990), Nassar and Huehn (1987), Kang and Pham (1991) and Thennarasu (1995). The genotypes with similar ranking across environments were considered as of stable yield performance (Farshadfar et al. 2014).

Hence, this study was conducted to quantify the magnitude of genotype $\times$ environment interaction by parametric and non parametric measures for feed barley genotypes evaluated under multi-location trials. The prime objectives of this study were to (i) interpret genotype-environment interaction by latest analysis procedures and (ii) association analysis among different measures as per the various statistics.

*Author for correspondence: <verma.dwr@gmail.com>. 


\section{Materials and Methods}

Twelve barley growing locations across the India were identified for evaluating 28 feed barley genotypes in field trials during cropping season 2013 - 2014. The randomized block design with four replications was laid out with recommended agronomical practices to ensure good harvest. The feed yield of genotypes were further analysed by statistical methods. The pedigrees of genotypes along with environmental conditions were given in Table 1 to highlight the variations in the considered locations. These promising genotypes are developed and contributed by various research centers under All India Wheat \& Barley Improvement programme of the country.

Environmental variance $\left(\mathrm{S}_{\mathrm{yi}}^{2}\right)$ : Lin et al. (1986) calculated environmental variance as stability measures for each genotype across test environments as: : $S_{y i}^{2}=\frac{\bar{\Sigma}\left(Y_{i j}-\Gamma_{i},\right)^{2}}{(B-1)}$

Superiority index $\left(\mathrm{P}_{\mathrm{i}}\right)$ : Genotypes with the largest yield difference as compared to highest yielder would have the highest $\mathrm{P}_{\mathrm{i}}$-value (Lin and Binns 1988) and calculated as $P_{i}=\frac{\sum_{i=i}^{H}\left(Y_{i j}-M_{j}\right)^{2}}{2 E}$

where $Y_{i j}$ is the yield of $i$-th genotype in environment $j, M_{j}$ is the maximum yield of the genotype at environment $\mathrm{j}$ and $\mathrm{E}$ is the number of environments.

Wricke's ecovalence $\left(\mathrm{W}_{\mathrm{i}}^{2}\right)$ denotes the contribution of each genotype to the $\mathrm{G} \times \mathrm{E}$ interaction sum of squares and calculated as: $W_{i}^{2}=\sum\left(Y_{i j}-\bar{Y}_{i .}-\bar{Y}_{. j}+\bar{Y}_{. .}\right)^{2}$

where $Y_{i j}$ observed yield of ith genotype for jth environment, $\overline{\mathbf{Y}}_{\text {i. }}$ average yield ith genotype

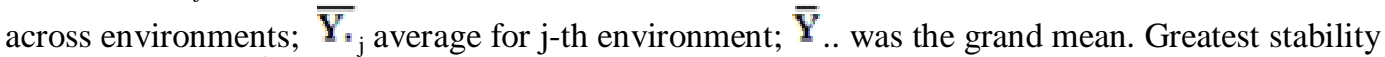
associated with $\mathrm{W}^{2}{ }_{\mathrm{i}}=0$.

Coefficient of variation $\left(\mathrm{CV}_{\mathrm{i}}\right)$ : Stability was also measured by $\mathrm{CV}_{\mathrm{i}}$ and genotypes with low $\mathrm{CVs}$ for yield were regarded as most desirable (Francis and Kannenberg 1978). $\mathrm{CV}_{\mathrm{i}}=\left(\mathrm{S}_{\mathrm{Yi}} / \overline{\mathbf{Y}}_{\mathrm{i}}\right) \mathrm{X}$ 100 .

Mohammadi and Amri (2008) defined geometric adaptability index (GAI) to evaluate the adaptability of genotypes and calculated as: $\mathrm{GAI}=\sqrt[n]{\prod_{\mathrm{k}=1}^{\mathrm{n}} \overline{\mathrm{Y}}_{\mathrm{k}}}$

in which $\overline{\mathrm{Y}}_{1}, \mathrm{Y}_{2}, \overline{\mathrm{Y}}_{3}, \ldots \overline{\mathrm{Y}}_{\mathrm{m}}$ are the mean yields of the first, second and $\mathrm{m}$-th genotype across environments and $\mathrm{n}$ is number of environments. Genotypes with high GAI will be desirable.

AMMI Stability Value (ASV) is the distance from the coordinate point to the origin in a twodimensional scatter graph of IPCA1 scores against IPCA2 scores (Purchase et al. 2000). AMMI Stability Value $(A S V)=\sqrt{\left[\frac{\text { SSIPCA1 }}{\text { SSIPCA2 }} \leqslant \text { IPCA1 score }\right]^{2}+\text { IPCA2 score }^{2}}$

where SSIPCA1 and SSIPCA2 are sum of squares by the IPCA1, IPCA2, respectively.

AMMI distance statistic coefficient (D) (Zang et al. 1998) was calculated as the distance of the interaction principal component (IPC) from the origin equals to $\sqrt{\sum_{i=1}^{n} \gamma_{i s}^{2}} \quad(i=1,2,3, \ldots \mathrm{n})$.

Non-parametric measures: Let $\mathrm{Y}_{\mathrm{ij}}$ denotes the phenotypic value of $\mathrm{i}$-th genotype in $\mathrm{j}$-th environment, where $\mathrm{i}=1,2, \ldots \mathrm{k}, \mathrm{j}=1,2, \ldots, \mathrm{n}$. Rank of the $\mathrm{i}$-th genotype in the $\mathrm{jth}$ environment denoted by $r_{i j}$ and the average rank of the i-th genotype across environments by $\overline{r_{i}}$. Karimzadeh 
et al. (2012) used the corrected yield of $\mathrm{i}$-th genotype in $\mathrm{j}$-th environment as $\left(\mathrm{Y}_{\mathrm{ij}}=\mathrm{Y}_{\mathrm{ij}}-\overline{\mathrm{Y}}_{t}+\overline{\mathrm{Y}}_{\mathrm{z}}\right)$ as $\mathrm{Y}_{\mathrm{ij}}$, was the corrected phenotypic value; $\overline{\mathrm{Y}}_{\mathrm{i}}$. was the mean of ith genotype in all environments and $\bar{Y}_{n}$ was the grand mean. The ranks obtained from these adjusted values $\mathrm{Y}_{\mathrm{ij}}$, depend only on GxE interaction and error effects. The ranks obtained from these adjusted values $\mathrm{Y}_{\mathrm{i}} \mathrm{i}$, depend only on $\mathrm{G} \times \mathrm{E}$ interaction and error effects. The genotype with the highest adjusted yield was given a rank of 1 and vice versa for lowest adjusted yielder. Nonparametric measures were calculated based on the ranks assigned by corrected values of yield to genotypes as:

$$
\begin{array}{ll}
S_{i}^{(1)}=\frac{2 \sum_{j}^{m-1} \sum_{j=j+1}^{m}\left|r_{i j}-r_{i j}\right|}{[m(m-1)]} & S_{i}^{(2)}=\frac{\sum_{j=1}^{m_{1}}\left(r_{j}-\bar{r}_{i}\right)}{(m-1)} \quad S_{i}^{(3)}=\frac{\sum_{j=1}^{m}\left(r_{i j}-\bar{r}_{i}\right)^{2}}{\bar{r}_{i+}} \\
S_{i}^{(4)}=\sqrt{\frac{\sum_{j=1}^{m}\left(r_{i j}-\bar{r}_{i}\right)^{2}}{m}} & S_{i}^{(5)}=\frac{\sum_{j=1}^{m}\left|r_{i j}-\bar{r}_{i}\right|}{m} \quad S_{i}^{(6)}=\frac{\sum_{j=1}^{m}\left|r_{i j}-\bar{r}_{i}\right|}{\bar{r}_{i-}}
\end{array}
$$

Non-parametric measures of Thennarasu's (1995) considered $\mathrm{r}_{\mathrm{ij}}^{*}$ was the rank of $\mathrm{Y}_{\mathrm{ij}}^{*}$, and $\overline{\bar{r}_{i}}$ and $\mathrm{M}_{\mathrm{di}}$ were the mean and median ranks for original, where $\bar{r}_{\vec{i}}{ }^{*}$ and $\mathrm{M}_{\mathrm{di}}^{*}$ were the same parameters computed from the corrected yield values. SAS-based computer program SASGESTAB (Hussein et al. 2000) was employed to calculate non-parametric measures.

$$
\begin{array}{ll}
N P_{i}^{(1)}=\frac{1}{m} \sum_{j=1}^{m}\left|r_{i j}^{*}-M_{d i}^{*}\right| & N P_{i}^{(2)}=\frac{1}{m}\left(\frac{\sum_{j=1}^{m}\left|r_{i j}^{*}-M_{d i}^{*}\right|}{M_{d i}}\right) \\
N P_{i}^{(3)}=\frac{\sqrt{\Sigma\left(r_{i j}^{*}-r_{i}^{*}\right)^{n} / m}}{\bar{r}_{i}} & N P_{i}^{(4)}=\frac{2}{m(m-1]}\left[\sum_{j=1}^{m-1} \sum_{j=j+1}^{m} \frac{\left|r_{i j}^{*}-r_{i j}^{*}\right|}{n_{i}}\right]
\end{array}
$$

\section{Results and Discussion}

AMMI analysis of variance yielded highly significant $(\mathrm{p}<0.01)$ differences among environments, genotypes and interaction effects (Table 2). The highly significant $\mathrm{G} \times \mathrm{E}$ interaction confirmed the differential response of genotypes in various environments and about $42.3 \%$ of the total variance accounted by interaction effect. Of the total variance, a larger portion was described by the environmental effects (36.4\%) while the genotypes accounted merely $6.9 \%$ of total variation. Significant interaction effects were further partitioned into four IPCAs which explained $32.2,20.3,15.6$ and $10.5 \%$ of the interaction sum of squares, respectively. First two components accounted for more than $50 \%$ of the interaction sum of squares.

Genotype G20(BH946) observed as highest yielder was followed by G19(RD2552) and G21(HUB113) (Table 3) whereas G10(RD2876), G9(RD2877) and G12(UPB1042) were lower yielders.

G22 (RD 2786) followed by G10 (2876) had large negative IPCA1 score as well as positive IPCA3 and IPCA4 value, respectively (Table 3 ). This is referred to as crossover $\mathrm{G} \times \mathrm{E}$ interaction response. G26 (RD 2854) and G4 (BH 981) genotypes showed negative and positive IPCA1 values, respectively. G26 (RD 2874) and G4 (BH 981) yielded more than overall mean and lower absolute IPCA1 scores had a combination of high yield and stable performance.

AMMI stability index (D) incorporates the scores of significant IPCA towards the interaction SS and the lower D values indicate high stability across the tested environments and vice versa 
(Zang et al. 1988). G23 (1.32) < G2 (1.42) < G20 (1.47) <G21 (1.63) i.e. genotypes were arranged in as per D values. G10 (RD 2876) and G24 (RD2877) expressed lowest yield along with larger D values of 3.19 and 3.49 , respectively.

Table 1. Details of feed barley genotypes, parentage and environmental conditions.

\begin{tabular}{|c|c|c|c|c|c|c|c|}
\hline Code & Genotype & Parentage & & Locations & $\begin{array}{l}\text { Altitude } \\
\text { (m) }\end{array}$ & Latitude & Longitude \\
\hline G1 & HUB 236 & DL88/22nd 1BYT15 & E1 & Durgapura & 390 & $26^{\circ} 51^{\prime} \mathrm{N}$ & $75^{\circ} 47^{\prime} \mathrm{E}$ \\
\hline G2 & KB 1353 & K508/RD2676 & E2 & Navgaon & 8.5 & $18^{\circ} 70^{\prime} \mathrm{N}$ & 7286' E \\
\hline G3 & NDB 1580 & NB3/HUB114 & E3 & Hisar & 215.2 & $29^{\circ} 10^{\prime} \mathrm{N}$ & $75^{\circ} 46^{\prime} \mathrm{E}$ \\
\hline G4 & BH 981 & RD2660/RD2683 & $\mathrm{E} 4$ & Ludhiana & 247 & $30^{\circ} 56^{\prime} \mathrm{N}$ & $75^{\circ} 52^{\prime} \mathrm{E}$ \\
\hline G5 & KB 1369 & Jaqriti/K169 & E5 & Varanasi & 75.5 & $25^{\circ} 20^{\prime} \mathrm{N}$ & $83^{\circ} 03^{\prime} \mathrm{E}$ \\
\hline G6 & HUB 237 & EIBGNOT-18/RD250B & E6 & Rewa & 365.7 & $24^{\circ} 31^{\prime} \mathrm{N}$ & $81^{\circ} 15^{\prime} \mathrm{E}$ \\
\hline G7 & BH 982 & '13" EMBSN-14/RD2683 & E7 & Faizabad & 113 & $26^{\circ} 47^{\prime} \mathrm{N}$ & $82^{\circ} 12^{\prime} \mathrm{E}$ \\
\hline G8 & BH 980 & NBD1276/8H393 & E8 & Kanpur & 125.9 & $26^{\circ} 29^{\prime} \mathrm{N}$ & $80^{\circ} 18^{\prime} \mathrm{E}$ \\
\hline G9 & RD 2875 & RD2552/PL419//RD2508 & E9 & Vijapur & 41.1 & $23^{\circ} 35^{\prime} \mathrm{N}$ & $72^{\circ} 55^{\prime} \mathrm{E}$ \\
\hline G10 & RD 2876 & RD266O/PENCO/CHEVRON-BAR & E10 & Udaipur & 582 & $24^{\circ} 34^{\prime} \mathrm{N}$ & $70^{\circ} 42^{\prime} \mathrm{E}$ \\
\hline G11 & UPB 1040 & IBON-LRA-M-31 (EIBGN 2010-11-30) & E11 & SK Nagar & 154.52 & $24^{\circ} 19^{\prime} \mathrm{N}$ & $72^{\circ} 19^{\prime} \mathrm{E}$ \\
\hline G12 & UPB 1042 & INBYT-LRA-M-17 (EIBGN 2010-11) & E12 & 2 Banswara & 216.44 & $23^{\circ} 55^{\prime} \mathrm{N}$ & $74^{\circ} 45^{\prime} \mathrm{E}$ \\
\hline G13 & JB 291 & DL88/K633 & & & & & \\
\hline G14 & PL 880 & PL426/BC473 & & & & & \\
\hline G15 & BH 902 & BH495/RD2552 & & & & & \\
\hline G16 & PL 881 & PL426/K537 & & & & & \\
\hline G17 & JYOTI & K 12/C 251 & & & & & \\
\hline G18 & PL 751 & K226/PL226 & & & & & \\
\hline G19 & RD 2552 & RD2035/DL472 & & & & & \\
\hline G20 & BH 946 & BHMS22A/BH549 //RD2552 & & & & & \\
\hline G21 & HUB 113 & KARAN2BO/C138 & & & & & \\
\hline G22 & RD 2786 & RD2634/NDB1020//K425 & & & & & \\
\hline G23 & JB 290 & JB58/RD25OB & & & & & \\
\hline G24 & RD 2877 & RD2052/DWR64//RD2660 & & & & & \\
\hline G25 & UPB 1041 & IBON-HI-33 (EIBGN 2012-13-45) & & & & & \\
\hline G26 & RD 2874 & NDB $1173 /$ BH902// RD27I5 & & & & & \\
\hline G27 & NDB 1578 & BCB128/NDB940 & & & & & \\
\hline G28 & KB 1367 & PFCBO23/MSEL & & & & & \\
\hline
\end{tabular}

Least AMMI Stability Value (ASV) score observed for G26 (KB1367), followed by G23 (JB 290), G11 (UPB1040) and G12 (UPB1042) were the stable one, while G22 (RD2786) and G9 (RD2875) were of unstable yield performance (Table 3).

Genotype's variance across environments and coefficient of variation were listed in Table 3. Genotypes G26 (RD 2874) and G27 (NDB 1578) were observed as of desirable performance as per these criteria and also non-stable performance of G10 (RD 2876) followed by G6 (HUB 237) and G24 (RD 2877). 
The least superiority index $\left(\mathrm{P}_{\mathrm{i}}\right)$ was considered for desirable genotype. The condition satisfied by G20 (BH 946), G21(HUB 113) was followed by G19 (RD 2552), G14 (PL 880).

Stable genotypes according to Wricke's ecovalence were G11 (UPB 1040) and G12 (UPB 1042). Higher values for unstable yield were observed for G16 (PL 881) and G9(RD 2875) genotypes.

Table 2. AMMI analysis of feed barley genotypes.

\begin{tabular}{llllll}
\hline $\begin{array}{l}\text { Source of } \\
\text { variation }\end{array}$ & $\begin{array}{l}\text { Degree of } \\
\text { freedom }\end{array}$ & $\begin{array}{l}\text { Mean Sum of } \\
\text { squares }\end{array}$ & $\begin{array}{l}\text { Variance } \\
\text { ratio }\end{array}$ & $\%$ TSS & $\begin{array}{c}\% \\
\mathrm{G} \times \mathrm{E}\end{array}$ \\
\hline Treatments & 335 & 437.4 & 18.17 & 85.63 & \\
Genotypes & 27 & 439.4 & 18.26 & 6.93 & \\
Environments & 11 & 5669.1 & 169.23 & 36.44 & \\
Block & 36 & 33.5 & 1.39 & & \\
Interactions & 297 & 243.4 & 10.12 & 42.25 & \\
IPCA 1 & 37 & 628.2 & 26.10 & & 32.15 \\
IPCA 2 & 35 & 418.3 & 17.38 & & 20.25 \\
IPCA 3 & 33 & 341.6 & 14.20 & & 15.59 \\
IPCA 4 & 31 & 245.0 & 10.18 & & 10.51 \\
Residuals & 161 & 96.5 & 4.01 & & \\
Error & 972 & 24.1 & & & \\
Total & 1343 & 127.4 & & & \\
\hline
\end{tabular}

$\% \mathrm{TSS}$, percentage of total sum of squares, $\% \mathrm{G} \times \mathrm{E}$, percentage of $\mathrm{G} \times \mathrm{E}$ total sum of squares $* * *$ denotes significant at 0.001 level of significance.

Non-parametric descriptive statistics based on original ranks, mean of ranks (MR), standard deviation of ranks (SD) and coefficient of variation of ranks (CV) identified G11(UPB1040) and G25(UPB1041) of stable performance, while unstable nature of G10(RD2876) and G24(RD2877) by MR, G16(PL881) and G9(RD2875) by SD and G19(RD2552) and G14(PL880) by CV, were also noticed. Simple descriptive statistics based on ranks discriminated among genotype performance (Karimzadeh et al. 2012). Genotype G25(UPB1041), G16(PL881) followed by G19(RD2552) were the unstable as well as G19(RD2552), G11(UPB1040) and G12(UPB1042) were of stable performance based on a corrected dataset that produced a mean of corrected ranks (CMR), standard deviation of corrected ranks (CSD), coefficient of variation of corrected ranks (CCV). First four nonparametric measures $\left(\mathrm{S}_{\mathrm{i}}^{1}, \mathrm{~S}_{\mathrm{i}}^{2} \mathrm{~S}_{\mathrm{i}}^{3}, \mathrm{~S}_{\mathrm{i}}^{4}\right)$ observed G11(UPB1040) and G16(PL881) as stable and unstable genotypes, respectively (Mortazavian and Azizinia 2014), however, last two measures selected G11(UPB1040) and G12(UPB1042) as of stable performance whereas G16(PL 881) and G24(RD 2877) by $S_{i}^{5}$ and G9(RD 2875) and G15(BH 902) by $S_{i}{ }^{6}$ for unstable performance. All measures were selected G11 (UPB1040) as desirable genotype for stable and G16(PL881) for unstable behavior for the considered set of feed barley genotypes.

Significant tests for $\mathrm{S}_{\mathrm{i}}{ }^{1}$ and $\mathrm{S}_{\mathrm{i}}{ }^{2}$ were developed by Nassar and Huehn (1987). Since sum of $\mathrm{Z}_{\mathrm{i}}^{1}=33.19$ and $\mathrm{Z}_{\mathrm{i}}^{2}=44.16$ were more than critical value of $\chi^{2}=31.41$, there were significant differences among the genotypes grown in the 12 environments (Sisay and Sharma 2016). Unstable performance of a few genotypes judged by large $\mathrm{Z}$ values as compared to the critical value of $\chi^{2}$ at $5 \%$ level of significance for one degree of freedom is i.e. 3.84. 


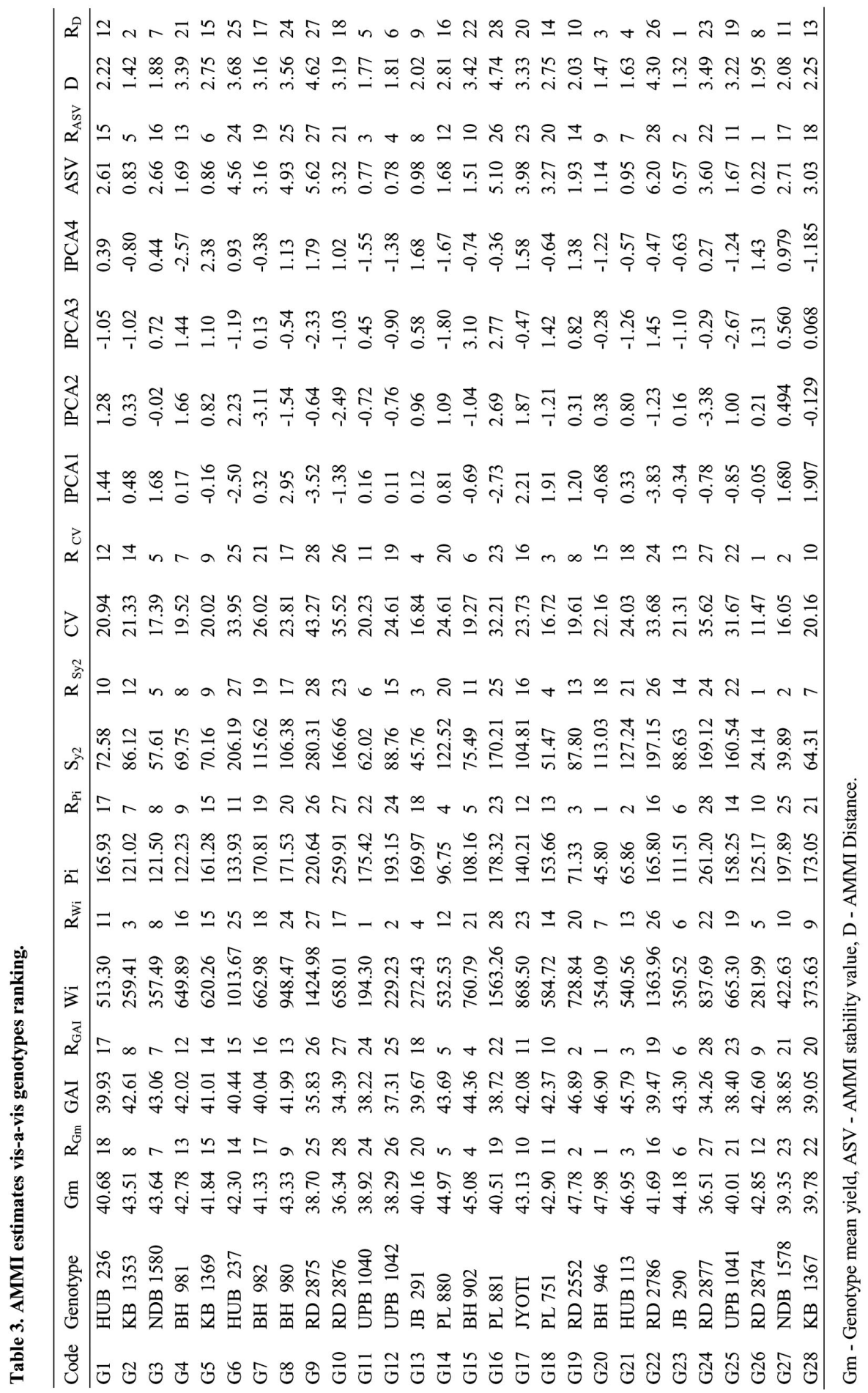




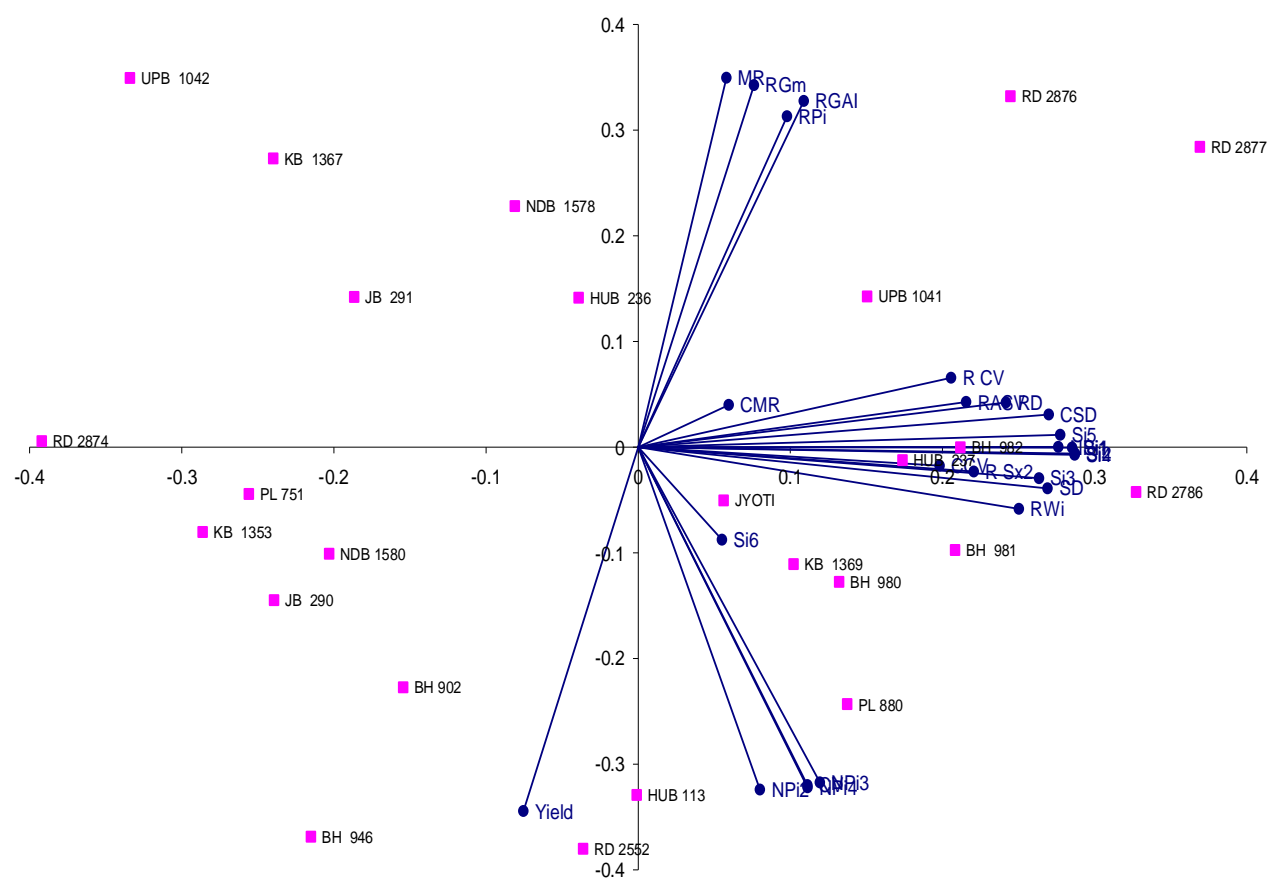

Fig.1. Biplot analysis of feed barley genotypes.

Yield values showed highly significant $\left(\mathrm{p}<0.01\right.$ ) positive rank correlation with $\mathrm{R}_{\mathrm{GAI}}, \mathrm{R}_{\mathrm{Pi}}$, $\mathrm{MR}, \mathrm{CMR}$ and highly significant negative association with $\mathrm{CV}, \mathrm{CCV}, \mathrm{NP}_{\mathrm{i}}^{(2)}, \mathrm{NP}_{\mathrm{i}}^{\left({ }^{(3)}\right.}, \mathrm{NP}_{\mathrm{i}}^{(4)}(\mathrm{Scapim}$ et al. 2010). Yield also expressed direct low correlation with $\mathrm{R}_{\mathrm{CV}}, \mathrm{S}_{\mathrm{i}}{ }^{3}, \mathrm{~S}_{\mathrm{i}}{ }^{4}$ and $\mathrm{NP}_{\mathrm{i}}{ }^{(1)}$.. MR had low positive relation with $\mathrm{NP}_{\mathrm{i}}^{(1)}, \mathrm{NP}_{\mathrm{i}}^{(2)}, \mathrm{NP}_{\mathrm{i}}^{(3)}$ and $\mathrm{NP}_{\mathrm{i}}^{(4)}$ whereas significant positive relationship with $\mathrm{S}_{\mathrm{i}}{ }^{1}, \mathrm{~S}_{\mathrm{i}}{ }^{2}, \mathrm{~S}_{\mathrm{i}}^{3} \mathrm{~S}_{\mathrm{i}}^{4}, \mathrm{~S}_{\mathrm{i}}^{5}$ and $\mathrm{S}_{\mathrm{i}}^{6}$ (Mortazavian and Azizinia 2014). $\mathrm{S}_{\mathrm{i}}{ }^{1}, \mathrm{~S}_{\mathrm{i}}{ }^{2}, \mathrm{~S}_{\mathrm{i}}^{3}, \mathrm{~S}_{\mathrm{i}}^{4}, \mathrm{~S}_{\mathrm{i}}^{5}$ and $\mathrm{S}_{\mathrm{i}}^{6}$ showed only direct relation with all measures and significant positive association among themselves (Zali et al. 2011).

Principal component (PC) analysis based on the rank correlation matrix was performed and presented in Fig. 1. Group I included the MR, $R_{\mathrm{Gm}}, \mathrm{R}_{\mathrm{GAI}}$ and $\mathrm{R}_{\mathrm{Pi}}$. Yield has been placed in first quadrant and showed right angle with the measures clustered in group 1. Measures in quadrant 2 split into two sub groups with $\mathrm{NPi}^{\mathrm{s}}$ separated themselves from $\mathrm{Si}^{\mathrm{s}}$ as well as with $\mathrm{R}_{\mathrm{Wi}}, \mathrm{R}_{\mathrm{Sx} 2}$ and $\mathrm{CCV}$. Sub groups of $\mathrm{NPi}^{2}, \mathrm{NPi}^{3}$ and $\mathrm{NPi}^{4}$ showed acute angle with yield values. However, yield maintained right angle with measures of subgroups comprises of $\mathrm{Si}^{\mathrm{s}}$.

Hierarchical clustering of genotypes by Ward's method performing the cluster analysis revealed four distinct clusters among 28 genotypes: cluster I consisted of stable and low yielders genotypes G11(UPB1040), G12(UPB1042), G13(JB291), G1(HUB236), G27(NDP1578), G28(KB1367) and next cluster of seven genotypes consisted of higher yielder genotypes G20(BH946), G23(JB 290), G21(HUB113), G15(BH902), G18(PL 751), G26(RD2874), G3(NDB1580). Third cluster of nine genotypes comprised of unstable genotypes as per $\mathrm{NPi}^{\mathrm{s}}$ with high yielder G19(RD2552). Finally, fourth cluster grouped highly unstable genotypes as per parametric, AMMI based along with non-parametric measures. 


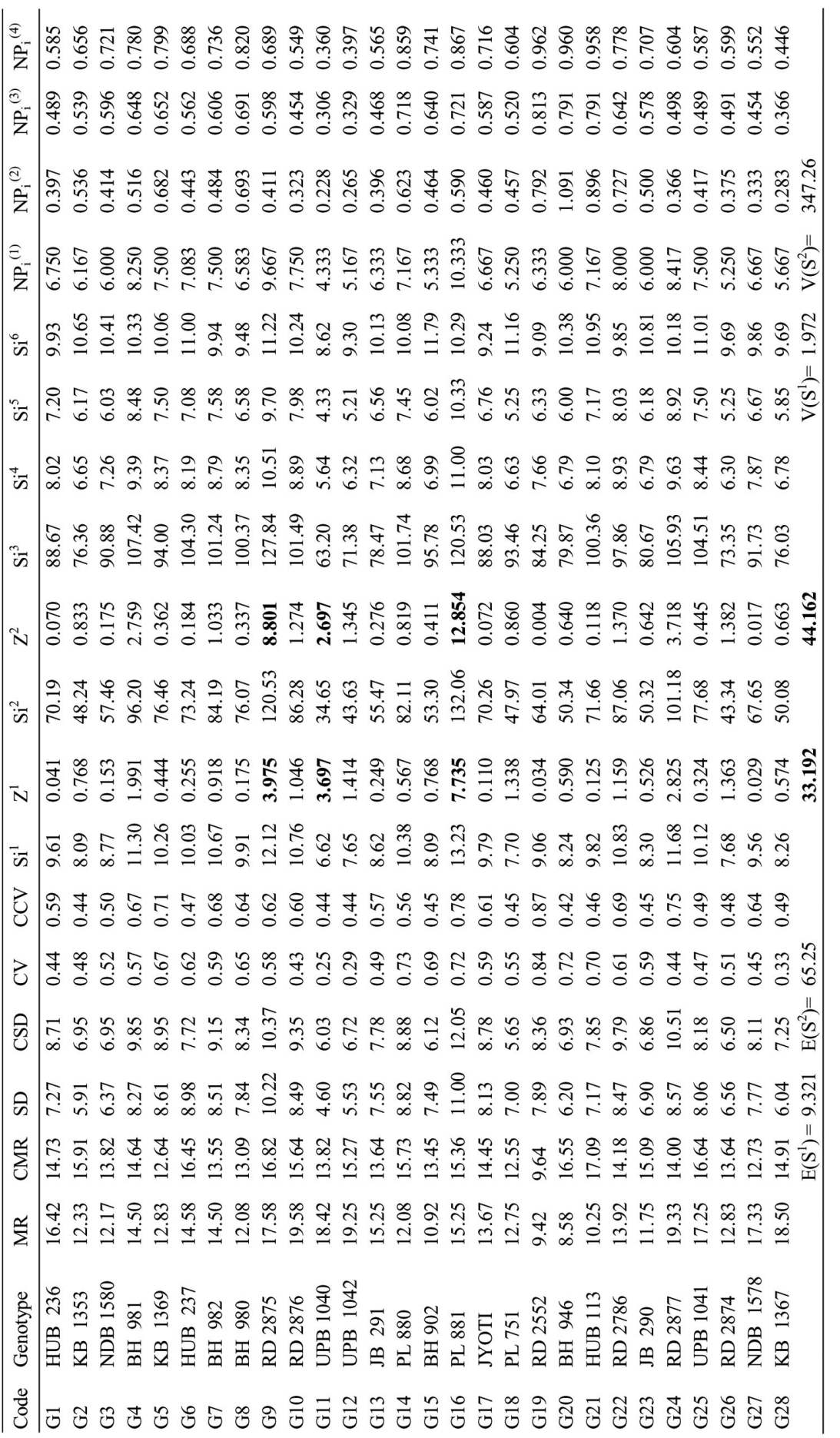




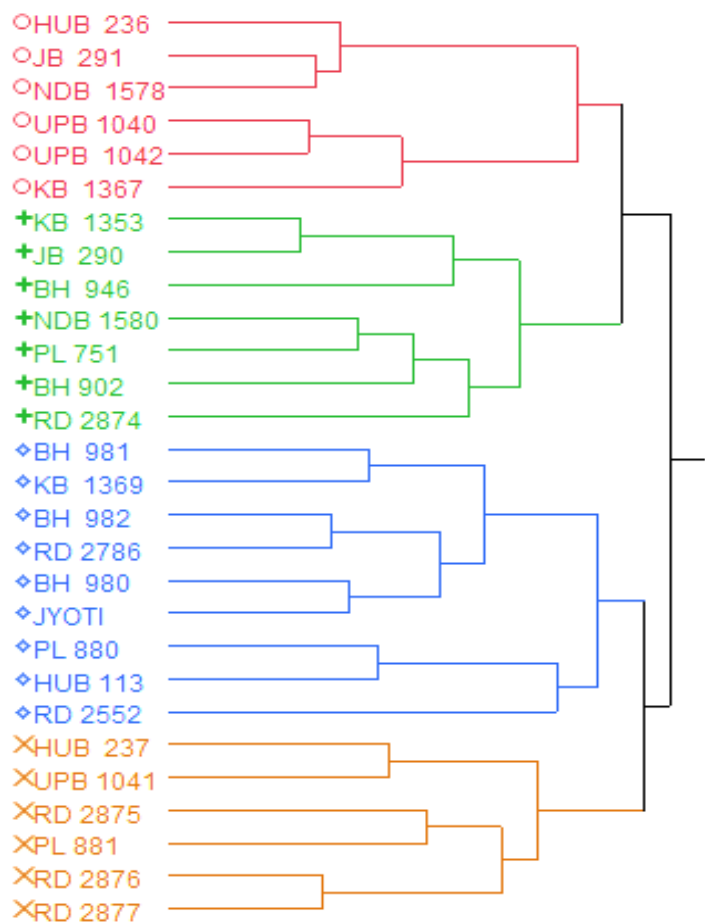

Fig. 2. Ward's clustering of genotypes.

Non-parametric (Thennarasu 1995) indices expressed the consistent performance of G11 (UPB1040), G12 (UPB1042) for stable yield as compared to G20 (BH 946), G21 (HUB113) along G19 (RD2552) as unstable genotypes (Table 4). The selection of $\mathrm{NP}_{\mathrm{i}}^{(1)}$ was different from rest

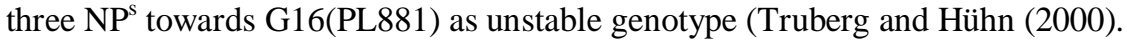

Parametric methods may not perform well if certain assumptions are violated. Non-parametric measures provide a useful alternative. These considerations supported the use of different parametric and non-parametric methods. Biplot analysis revealed strong to moderate association among parametric / non-parametric measures. Results favour the genotypes G20(BH946), G19(RD2552) and G21(HUB113) for further inclusion in the breeding program.

\section{Acknowledgements}

The multi-environment trials of feed barley genotypes were performed at AICW\&BIP centers across the country. Authors sincerely acknowledge the hard work of the staffs at these centers to carry out the field layout and data recording.

\section{References}

Annicchiarico P, Bellah F and Chiari T 2005. Defining sub regions and estimating benefits for a specificadaptation strategy by breeding programs. Crop Sci. 45: 1741-1749.

Farshadfar E, Mahmudi N and Sheibanirad A 2014. Non-parametric methods for interpreting genotypexenvironment interaction in bread wheat genotypes. J. Biol. \& Env. Sci. 4: 55-62.

Francis TR and Kannenberg LW 1978. Yield stability studies in the short season maize. I. A descriptive method for grouping genotypes. Can. J. Pl. Sci. 58: 1029-1034. 
Huehn M 1990. Non-parametric measures of phenotypic stability: Part 2. Application. Euphytica 47: 195-201.

Hussein MA, Bjornstad A and Aastveit AH 2000. SASG $\times$ ESTAB: A SAS program for computing genotype $\times$ environment stability statistics. Agron. J. 92: 454-459.

Kang MS and Pham HN 1991. Simultaneous selection for high yielding and stable crop genotypes. Agron. J. 83:161-165.

Karimizadeh R, Mohammadi M, Sabaghnia N and Shefazadeh MK 2012. Using Huehn's nonparametric stability statistics to investigate genotype $\times$ environment interaction. Not. Bot. Horti. Agrobo. 40: 195200.

Lin CS and Binns MR. 1988. A superiority measure of cultivar performance for cultivar $\times$ location data. Can. J. Pl. Sci. 68: 193-198.

Lin CS, Binns MR and Lefkovitch LP 1986. Stability analysis: where do we stand? Crop Sci. 26: 894-900.

Mohammadi R and Ahmed A 2008. Comparison of parametric and non-parametric methods for selecting stable and adapted durum wheat genotypes in variable environments. Euphytica 159: 419-432.

Mohammadi R, Farshadfar E and Amri A 2016. Comparison of rank-based stability statistics for grain yield in rainfed durum wheat. New Zealand J. Crop \& Hort. Sci. 44(1): 25-40.

Mohammadi R and Amri A 2008. Analysis of genotype $\times$ environment interaction for grain yield in durum wheat. Crop Sci. 49: 1177-1186.

Mortazavian SMM and Azizinia S 2014. Non-parametric stability analysis in multi-environment trial of canola. Tur. J. Field Crops. 19(1): 108-117.

Nassar R and Huehn M 1987. Studies on estimation of phenotypic stability: Tests of significance for nonparametric measures of phenotypic stability. Biometrics 43: 45-53.

Purchase JL, Hatting H and Van Deventer CS 2000. Genotype $\times$ environment interaction of winter wheat in south Africa: II. Stability analysis of yield performance. S Afr. J. Plant Soil. 17(3): 101-107.

Scapim CA, Pacheco CAP, do Amaral ATJúnior, Vieira RA, Pinto RJB and Conrado TV 2010. Correlations between the stability and adaptability statistics of popcorn cultivars. Euphytica 174: 209-218.

Sisay A and Sharma M 2016. Parametric and non-parametric methods to describe genotype by environment interaction and grain yield stability of bread wheat. Stat. \& App. 14(1\&2): 9-29.

Suadric A, Simic D and Vrataric M 2006. Characterization of genotype by environment interactions in soybean breeding programmes of southeast Europe. Pl. Breed. 125: 191-194.

Thennarasu K 1995. On certain non-parametric procedures for studying genotype $\times$ environment interactions and yield stability. Ph.D. Thesis. P.J. School, IARI, New Delhi, India.

Truberg B and Hühn M 2000. Contributions to the analysis of genotype $\times$ environments interactions: Comparison of different parametric and non-parametric tests for interactions with emphasis on crossover interaction. J. Agron. Crop Sci. 185: 267-274.

Ward JH 1963. Hierarchical grouping to optimize an objective function. J. Amer. Stat. Assoc. 58: 236-224.

Wricke G 1962. Über eine Methode zur Erfassung der ökologischen Streubreite in Feldversuchen. Z. Pflanzenzüchtg 47: 92-96.

Zali H, Farshadfar E and Sabaghpour H 2011. Non-parametric analysis of phenotypic stability in chickpea (Cicer arietinum L.) genotypes in Iran. Crop Breed. J. 1: 85-96.

Zhang Z, Lu C and Xiang ZH 1998. Analysis of variety stability based on AMMI model. Acta Agron. Sin. 24: 304-309.

(Manuscript received on 17 June, 2017; revised on 12 September, 2018) 